\title{
HE DYNAMICS OF TRUST AND CONTROL IN INNOVATION ECOSYSTEMS
}

Within the innovation ecosystem literature, scholars have considered governance mechanisms as an important instrument for focal entities to mitigate the risks of opportunistic behaviour. Scholars have not focused yet on how these mechanisms work. In the alliance literature, governance mechanisms have been extensively researched and described. As innovation ecosystems are a subset of alliances, constructs from the alliance literature are used to understand how governance mechanisms are employed by the focal entity within innovation ecosystems. Scholars have also considered the importance of partner alignment for successful innovations. To mitigate the risks of opportunistic behaviour and to align partners, this research has focused on understanding how the focal entity uses governance mechanisms to influence partner alignment. Based on an exploratory multiple case study research, this research has found a list of partner stimulators, like for example leadership and expectation management that influence the effectiveness of governance mechanisms used by focal entities in aligning partners. When partner alignment stimulators are present, the effectiveness of governance mechanisms is enhanced and partners feel more aligned. We have also developed a model that explains the relation between partner alignment stimulators, governance mechanisms, and partner alignment. In addition, we have found that constructs from the alliance literature can be applied to an innovation ecosystem setting when partner alignment stimulators are considered in addition to governance mechanisms. We contribute to the innovation ecosystem literature by explicitly considering partner alignment stimulators that influence the relation between governance mechanisms and partner alignment. Future research could focus on using quantitative methods to strengthen the findings of this research.

Keywords: Innovation Ecosystem; Governance Mechanisms; Focal Entity; Alliances; Output Control; Social Control; Behavioural Control; Competence Trust; Goodwill Trust; Partner Alignment; Alliance Management Capabilities.

\footnotetext{
${ }^{1}$ Open University of the Netherlands, Netherlands.

Orcid: < http://orcid.org/0000-0002-0383-8365> Email: < dieudonnee.cobben@ou.nl>

2 Open University of the Netherlands, Netherlands..

Orcid: < http://orcid.org/0000-0001-5475-2222> Email: < Nadine.Roijakkers@ou.nl>
} 


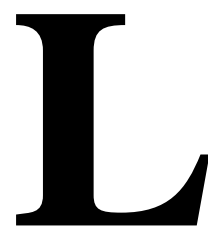

A DINÁMICA DE LA CONFIANZA Y EL CONTROL EN LOS ECOSISTEMAS DE INNOVACIÓN

\section{Resumen}

Dentro de la literatura sobre ecosistemas de innovación, los académicos han considerado los mecanismos de gobernanza como un instrumento importante para que las entidades focales mitiguen los riesgos de comportamiento oportunista. Los estudiosos aún no se han centrado en cómo funcionan estos mecanismos. En la literatura de la alianza, los mecanismos de gobierno han sido ampliamente investigados y descritos. Como los ecosistemas de innovación son un subconjunto de alianzas, los constructos de la literatura de alianzas se utilizan para comprender cómo los mecanismos de gobernanza son empleados por la entidad focal dentro de los ecosistemas de innovación. Los académicos también han considerado la importancia de la alineación de socios para innovaciones exitosas. Para mitigar los riesgos de comportamiento oportunista y para alinear a los socios, esta investigación se ha centrado en comprender cómo la entidad focal utiliza los mecanismos de gobierno para influir en la alineación de los socios. Sobre la base de una investigación exploratoria de estudios de casos múltiples, esta investigación ha encontrado una lista de estimuladores asociados, como por ejemplo el liderazgo y la gestión de expectativas, que influyen en la eficacia de los mecanismos de gobernanza utilizados por las entidades focales para alinear socios. Cuando los estimuladores de alineación de los socios están presentes, la efectividad de los mecanismos de gobernabilidad se mejora y los socios se sienten más alineados. También hemos desarrollado un modelo que explica la relación entre los estimuladores de alineación de socios, los mecanismos de gobierno y la alineación de socios. Además, hemos encontrado que las construcciones de la literatura de la alianza se pueden aplicar a un entorno de ecosistemas de innovación cuando se consideran los estimuladores de alineación de socios además de los mecanismos de gobernanza. Contribuimos a la literatura sobre ecosistemas de innovación considerando explícitamente los estimuladores de alineación de socios que influyen en la relación entre los mecanismos de gobernabilidad y la alineación de socios. La investigación futura podría centrarse en el uso de métodos cuantitativos para fortalecer los hallazgos de esta investigación.

Palabras clave: ecosistema de innovación, mecanismos de gobierno, entidad focal, alianzas, control de resultados, control social, control de comportamiento, confianza de competencia, confianza de buena voluntad, alineación de socios, capacidades de gestión de alianzas.

Cite it like this:

Cobben, D., \& Roijakkers, N. (2018). The Dynamics of Trust and Control in Innovation Ecosystems. International Journal of Innovation, 7(1), 01-25. http://dx.doi.org/10.5585/iji.v7i1.341 


\section{INTRODUCTION}

Innovation ecosystems have the potential to produce innovations for sustained industrial competitiveness by offering an innovative environment that allows for multidisciplinary collaboration (Adner, 2006; Wang, 2009). These ecosystems are collaborative agreements where a wide variety of partners combine their individual technologies and/or services into a valuable innovation. Typically, a focal entity governs this arrangement (Gobble, 2014) and facilitates joint value capture and creation via partner alignment (Adner, 2006; Adner and Kapoor, 2010; Adner, 2017).

Value capture and creation within ecosystems represents a complicated process as it can be difficult to create a sense of collective value (Lopes-Berzosa and Gawer, 2014) and/or to ensure that actors behave in congruence with the interest of the ecosystem instead of behaving opportunistically - that is acting out of self-interest (Boudreau, 2010). When partners in an innovation ecosystem perceive a risk of opportunistic behaviour, they will do everything to protect themselves (Das and Teng, 1998; Das and Teng, 2001).

To mitigate the risk of opportunistic behaviour, governance mechanisms, that is trust and control based governance mechanisms, can be used (Gulati, 1995; De Man and Roijakkers, 2008). These mechanisms can be used by the focal entity to safeguard the system against opportunistic behaviour by creating mutual agreement (partner alignment).

Trust-based governance mechanisms aim to reduce opportunistic behaviour by creating internally motivated actors by the presence of trust (De Man and Roijakkers, 2008; Gulati, 1995) whereas control-based governance mechanisms do so by means of formal rules and procedures (De Man and Roijakkers, 2008).

Within the innovation ecosystem literature, the importance of both trust (Bercovitz, Jap, and Nickerson, 2006; Autio and Thomas, 2014) and control-based governance mechanisms (Adner and Kapoor, 2010) as well as the role of the focal entity in its implementation (Adner, 2017; Jacobides, Cennamo, and Gawer, 2018) have been considered as driving factors for partner alignment. To the best of our knowledge no research has been done yet to understand the implementation of governance mechanisms by the focal entity in innovation ecosystems.

Therefore scholars call for more research (e.g., Maes and Roijakkers, 2017; De Man and Roijakkers, 2008; Adner, 2017). So far, initial research regarding innovation ecosystems has been mainly based on interviews with focal entities (Vanhaverbeke, 2017); the opinions of the partners within ecosystems were often not considered.

As a result, there are not many insights yet on the internal dynamics within innovation ecosystems. To the best of our knowledge no empirical research has been done yet concerning the use of governance mechanisms by focal entities nor on the alignment of partners within innovation ecosystems (Meier, Lütkewitte, and Mellewigt, 2016; Adner, 2017).

Though no empirical research has been done yet within innovation ecosystems, trust and control-based governance mechanisms have been extensively researched in the alliance literature (e.g., Gulati, 1995; Hagedoorn, Roijakkers, and Van Kranenburg, 2008; De Man and Roijakkers, 2008). In the alliance literature, several types of both trust and control-based governance mechanisms have been identified (Das and Teng, 1998; Das and Teng, 2001). Innovation ecosystems are seen as a specific subset of alliances and networks (Gulati, Puranam, and Tushman, 2012); they have specific properties that distinguish them, for instance, their focus (Adner, 2017).

Given their specificities, it remains unclear whether we can directly use concepts from the alliance literature within an innovation ecosystem context. Research is required to understand how governance mechanisms are used within innovation ecosystems. 
As many unknowns remain in the use of governance mechanisms, many questions still remain. For instance, how are governance mechanisms used by focal entities within an innovation ecosystem context? And how effective are these governance mechanisms in aligning partners? Are focal entities able to align the partners in the ecosystem? As such, a need exists to further investigate the use of governance mechanism by focal entities in the context of innovation ecosystems. Therefore this article tackles the following research question:

How does the focal entity use governance mechanisms to influence partner alignment within the innovation ecosystem?

We address this question by means of an exploratory multiple case study with cases in the fields of blockchain, artificial intelligence, climate change, and sustainability. The results show that constructs from the alliance literature can be applied to an innovation ecosystem context only when an additional variable is considered; the partner alignment stimulator. When these stimulators are present, the focal entity is more effective in aligning partners via the use of governance mechanisms.

This implies that we augment the innovation ecosystem literature by understanding how the focal entity implements governance mechanisms within innovation ecosystems and what its effect is on partners within an innovation ecosystem.

By building upon the extant literature on alliances, this research provides an initial attempt to connect the fields of alliance and ecosystem literature to understand how different types of governance mechanisms are used by focal entities within innovation ecosystems and how this influences partner alignment.

Whereas most existing research has not focused yet on the how-question, this research is one of the first that provides insights in the dynamics of governance mechanisms in innovation ecosystems through empirical research.

The following section starts with an explanation of the innovation ecosystem and alliance concepts. Next, trust and control as governance mechanisms are characterized. After the theoretical aspects are explained, the method used to answer the research question is described. Next, the results of the study and a model are discussed. This research concludes with a discussion on how trust and control are used by focal entities in innovation ecosystems to influence partner alignment.

\section{THEORETICAL REFERENCE FRAMEWORK}

Firms have typically opted for internal innovation development. However, to respond quickly to complex changes in technology and customer demands, firms have started to collaborate with all kind of partners in the last two decades. Both innovation ecosystems and alliances are examples of collaborations between firms. Gulati et al. (2012) have stated that ecosystems partly overlap with alliances, forming a specific subset of alliances. Though in essence they both aim at collaboration, innovation ecosystems and alliances both have their own specificities.

First, alliances focus on the firm level, whereas innovation ecosystems focus on activities.

Second, in alliances the real purpose of the collaboration is often not revealed and value propositions are often not known, whereas in innovation ecosystems value propositions are leading (e.g. in attracting the right partners).

Third, alliances are generally not focused on developing knowledge and inventions, whereas ecosystems do specifically focus on these two activities (Adner, 2017).

Last and contrarily to alliances, ecosystems do not always contain formal alliances or binding forms (Jacobides et al., 2018). Innovation ecosystems are thus a standalone concept, requiring structure and resolved coordination challenges (Jacobides et al., 2018).

Different forms of trust and controlbased governance mechanisms and different risk types were identified in the alliance 
literature. As trust and control-based governance mechanisms have not been researched yet in an innovation ecosystem setting and innovation ecosystems are seen as a subset of alliances, in this article, definitions from the alliance literature regarding governance mechanisms are applied within an innovation ecosystem context. This is done to understand how focal entities use governance mechanisms in an innovation ecosystem context and how it influences the alignment of partners. In the following subsections the concepts innovation ecosystem, alliance, and governance mechanisms are briefly explained.

\section{Innovation ecosystems}

The innovation ecosystem is a unique collaboration where several actors combine their individual offerings into a specific innovation solution (Autio and Thomas, 2014). More specifically, these ecosystems involve relations that are not decomposable into a combination of multiple bilateral relations.

A wide variety of actors contribute material resources and human capital and collaboratively form the institutional environment required for successful innovation (Jackson, 2015). To materialize a value proposition, an alignment structure for the multilateral set of partners is required (Adner, 2017). Innovation ecosystems can deliver hightech solutions that firms are less likely to deliver on their own (Autio and Thomas, 2014; Adner and Kapoor, 2010).

Innovation ecosystems are typically governed by a focal entity. This entity can be either a technology platform, a set of social or economic conditions or a company (Gobble, 2014). The focal entity develops the ecosystem's strategy, institutional system, and governs the technological architecture (Adner and Kapoor, 2010; Autio and Thomas, 2014). Often, a focal entity first develops a value proposition and then tries to attract partners that are capable of contributing to the proposition.

Focal entities often use their position to control the technological architecture or valuecreating brand to enhance their own performance (Autio and Thomas, 2014). The ability of the focal entity to manage the network depends on its ability to influence and control the ecosystem, the match between the focal entity's goal and the ecosystem's goal, and the structure of the ecosystem (Möller, Rajala, and Svahn, 2005).

The success of an innovation developed by an innovation ecosystem depends on many different actors (Adner, 2006; Wang, 2009) as a variety of modules developed by different actors are combined into a (technological) solution (Mercan and Göktas, 2011; Wang, 2009). Members have their own internal challenges either upstream (suppliers) or downstream (complementors) - in the development process of their specific part that have to be resolved before an innovation can be delivered to customers (Adner and Kapoor, 2010).

Only when the focal entity, upstream component partners and downstream complementary partners cooperate, challenges can be resolved (Song, 2016). In order to collaborate and to solve the (internal) challenges, mutual agreement among partners is required.

Only when a focal entity is able to recognize that the interests of all partners have to be in line and that every partner has different perceptions of uncertainties and different strategies to handle these uncertainties, partners have an incentive to contribute to the ecosystem (Leavy, 2012; Gomes, Salerno, Phaal, and Probert, 2018).

The extent to which mutual agreement exists, expressed in terms of positions and flows, is also known as the level of alignment between partners. Mainly at the start of innovation ecosystems partners are still searching for compatible incentives and motives. When ecosystem development is more mature, the level of alignment often increases (Adner, 2017).

Partner alignment can be measured as the extent to which the focal entity and partners within the innovation ecosystem understand each other's interests and uncertainties (Adner, 2017; Leavy, 2012). The focal entity is responsible for partner alignment (Adner, 2017).

\section{Alliances}

Alliances are defined by Gulati (1995) as agreements between two or more firms regarding the pooling of resources to explore 
and exploit market opportunities. Alliances are used to retrieve resources and competences that are not internally available for firms. The transaction costs for starting and managing an alliance are lower than the costs to get acquainted with new knowledge from scratch.

Alliances are used by firms to obtain competitive advantages, to acquire new technologies, to enter new markets, to share risk with others, to establish economies of scale or to access complementary resources and technologies (Gulati, 1995). It can be a difficult process for firms to fully obtain the benefits from alliances as firms are mostly self-interested (opportunistic) and try to retrieve as much knowledge as possible for themselves (LeroiWerelds, Pop and Roijakkers, 2017). Collaborating companies put none to little effort in developing a common strategy; alliances rely upon the individual strategies of the involved companies (Roijakkers and Hagedoorn, 2006).

To manage the success of alliances, firms use alliance management capabilities. These capabilities comprise the capability of a firm to handle or manage an alliance (Anand and Khanna, 2000).

Alliance management capabilities are important as industries often develop in unexpected ways, making it a serious challenge for firms to manage their dynamics (Van de Ven and Polley, 1992; Madhok and Tallman, 1998).

Six alliance management capabilities are crucial: coordination, communication, bonding (Schreiner, Kale, and Corsten., 2009), interorganizational learning, sensing, and transformation (Schilke and Goerzen, 2010; Gomes et al., 2018).

Capabilities are developed by firms having either experience (Siminon, 1997; Hoang and Rothaermel, 2005) or taking deliberate actions to develop structural mechanisms (Kale, Dyer, and Singh, 2002). Alliance management capabilities mediate the effect between governance structures and alliance performance (Schilke and Goerzen, 2010).

\section{Governance mechanisms}

In alliances, different reasons are found that result in a lack of trust; uncertainties in the environment, the incomplete nature of contracts, bounded rationality, and the behaviour of partners (opportunism) (Williamson, 1975). To prevent opportunistic behaviour (e.g. evasion and violation of agreements (Wathne and Heide, 2000)), firms use governance mechanisms - either trust or control-based (Gulati, 1995).

Control-based governance mechanisms aim at reducing the likelihood that a partner behaves in an opportunistic manner and protects the company via the use of formal rules and procedures (De Man and Roijakkers, 2008; Das and Teng, 2001).

The use of control-based governance mechanisms makes it more expensive for organizations to implement activities that only benefit their own goals. The consequences of opportunistic behaviour are stipulated in contracts (i.e. fines) (Parkhe, 1993).

Control also specifies the labour division between firms; it functions as a guideline for the integration of activities, decision-making and how to act in case of disagreements (Faems, Janssens, Madhok, and Van Looy, 2008). There are different instruments to exercise control (Poppo and Zenger, 2002; Das and Teng, 2001; De Man, 2006).

Control can be classified into external measure-based control and internal value-based control. External measure-based control focuses on the establishment of formal rules, procedures, and policies to monitor and reward desirable outcome (Das and Teng, 2001). This form of control can be categorized into behavioural control and output control.

Behavioural control focuses on influencing the behaviour of partner firms via, for example, reporting devices, written notice of departure from agreements, accounting examinations, cost and quality controls, arbitration clauses and lawsuit provisions (Das and Teng, 1998).

Output control focuses on defining the preferred output of an alliance via setting alliance goals, establishment of incentive systems and reward structures, and formal monitoring procedures (Dekker, 2004).

Internal value-based control, also known as social- or clan control, focuses on the 
establishment of organizational norms, values, culture, and the internationalization of goals to encourage desirable behaviour and outcome (Das and Teng, 2001).

Social control does not define behaviour or output; it rather focuses on socialization via the development of organizational consensus. It aims at developing organizational norms, values, culture, and the internalization of goals to encourage desirable behaviour and outcomes (Das and Teng, 1998; Das and Teng, 2001).

In contrast to control, trust is presented in the literature as a more flexible governance form; it is based on positive expectations of partners. The more firms cooperate, the more trust increases and the less control is used (Gulati, 1995).

When trust-based governance mechanisms are used, every partner is allowed to join, leadership is decentralized, and cultural differences are valued leading to more longterm relations (De Man, 2006).

The aim is to reach complementary goals with internally motivated actors that trust one another (De Man and Roijakkers, 2008; Gulati, 1995). In the case of trust, firms worry less about opportunistic behaviour and, as such, reduce control-specific actions (Das and Teng, 2001).

In unpredictable environments, trust is a valuable mechanism as contracts are not able to fully capture the market dynamics (De Man and Roijakkers, 2008).

An initial level of mutual trust is required to start arrangements (Hagedoorn et al., 2008). Repeated ties (e.g. common history of collaborations) increase the level of trust (Hagedoorn et al., 2008; Gulati, 1995; Roijakkers, 2003).

Two different types of trust are classified; goodwill and competence trust. Goodwill trust focused on the expectation that a partner intends to fulfill its role and is influenced by previous experience with a partner.

Therefore, the goodwill is based on attitudes of specific personnel, also described as trust guardians (Child, 2001).

Goodwill trust is based on attitudes of specific personnel, previous experience or a common history (Lui and Ngo, 2004; Das and Teng, 1998; Das and Teng, 2001).
Competence trust is based on the expectation that a partner has the ability to fulfill its role and is based on resources and reputation of a partner (Das and Teng, 1998; Das and Teng, 2001).

In this section, different concepts were explained to understand the insights that the existing literature provides.

We have found that in the ecosystem literature the importance of governance mechanisms is only sparsely considered; scholars have only briefly mentioned, mainly in the form of future research directions, that governance mechanisms are important, but seem to show none to little understanding of how these mechanisms are exactly used and implemented by the focal entity within innovation ecosystems.

Also, findings regarding innovation ecosystems are mainly based on research of focal entities, ignoring the importance of other partners within innovation ecosystems. In the alliance literature governance mechanisms have been extensively described, also in relation to different types of alliances.

In the alliance literature also the use of management capabilities is described, which according to that literature stream, mediates the relation between governance structures and alliance performance.

As the innovation ecosystem has its own specificities compared to alliances, this article investigates whether it is meaningful to apply governance mechanisms as described in the alliance literature directly to innovation ecosystems and whether a construct comparable to alliance management capabilities is present in innovation ecosystems.

Still, as innovation ecosystems are a subset of alliances, it could be interesting to use the general definitions of different types of governance mechanisms from the alliance literature and investigate how governance mechanisms are used by focal entities within an innovation ecosystem setting.

When it is understood how the focal entities use governance mechanisms within innovation ecosystems, it also can be understood how focal entities influence partner alignment within the innovation ecosystem by means of these mechanisms. 


\section{METHOD Methodology}

This research was conducted by means of theoretical sampling, including four cases (Eisenhardt and Graebner, 2007). During this process, theory was generated by collecting and analyzing data at the same time.

The initial data generation was based on the overarching research topics; governance mechanisms, alliance management capabilities, and innovation ecosystems (Eisenhardt and Graebner, 2007).

The four cases were selected based on their suitability to elaborate upon the relationships between the constructs of interest.

More specifically, this research aimed at understanding how the focal entity within an innovation ecosystem influences the dynamics within the innovation ecosystem by means of governance mechanisms.

This study has an inductive character meaning that existing literature regarding alliances and innovation ecosystems was used to understand the use of different governance mechanisms by a focal entity and its effectiveness in aligning partners.

An exploratory multiple case study approach was chosen to enable initial research on the use of concepts from the alliance literature within innovation ecosystem research and to enable the identification of emerging themes (Edmonson and McManus, 2007).

A qualitative research design is appropriate, considering the limited understanding of the use of governance mechanisms in the innovation ecosystem literature, suggesting a need for explorative research (Adner, 2017).

Additionally, the impact of governance mechanisms on the partners within innovation ecosystems has not been considered yet, suggesting a further need for explorative research.

Third, it is not understood yet whether a moderating or mediating variable, comparable to alliance management capabilities, exists that influence the relation between governance structures and partner alignment within innovation ecosystems.

Last, the complexity and dynamic character of governance mechanisms in innovation ecosystems suggest a need for empirical research to create a first understanding of its implementation.

\section{Case selection}

All four cases reflect innovation ecosystems that focus on providing solutions to complex challenges. Also, all four cases display a combination of both control and trust-based governance mechanisms that are implemented by the focal entity.

Relatively young ecosystems were chosen, as starting ecosystems are the most appropriate for displaying the dynamics of governance mechanisms. More specifically, at the start, partners still have to align to find compatible incentives and motives.

Over time, activities, actors, positions, and links become stable and the impact of (new) governance mechanisms is likely to decrease and then it can become more difficult to understand the dynamics (Autio and Thomas, 2013; Adner, 2017).

Notably, the cases differ in, for example, their industrial background, number of actors, actor sizes, actor types, used technology, institutional environment and location - aiding generalizability of the results in case of comparable results (Eisenhardt and Graebner, 2007).

As all cases are still substantially different, the reliability of the research is discussable.

Still, as procedures have been followed and documented, external reviewers could check the reliability of this case study method by repeating the procedures for the same case study (Yin, 2013).

The researched ecosystems were labeled as innovation ecosystems as they all fulfill a number of conditions of innovation ecosystems.

First, each ecosystem is managed by a focal entity that orchestrates the ecosystem (Autio and Thomas, 2014; Adner and Kapoor, 
2010; Adner, 2017). Also, the participants of the ecosystem deliver the input for innovation; suppliers, research and educational organizations, and customers are integrated into the innovation process (Adner and Kapoor, 2010).

Third, in all ecosystems the partner alignment structure is under development (Adner, 2017). Last, the relationships in the four ecosystems are not decomposable to bilateral interactions (Adner, 2017).

\section{Data collection and data sources}

We collected data by means of conducting semi-structured interviews and by consulting a variety of (online) sources of documentation.

The first step of the data collection was to understand how the focal entity uses governance mechanisms in innovation ecosystems. The second step was to understand the impact of governance mechanisms implemented on partners within the ecosystem.

The third step was to find out whether moderating or mediating variables are present that influence the relation between governance structures and innovation ecosystem performance. Looking beyond the focal entity makes data collection more complex, but enhances insights as single-respondent bias in a network context is prevented (Eisenhardt, 1989).

Semi-structured interviews (22 in total) with key persons (i.e., representatives of organizations) were the most important information source. The interviews were conducted with both focal entities and partners active within the ecosystems.

When interviewees mentioned the use of a governance mechanisms or when signs of ineffectiveness were found, follow-up questions were asked to discover how and why they were implemented and what their impact was.

The questions for the interviews were based on both the alliance and innovation ecosystem literature. Interviews were continued until convergence was achieved. Interviews were conducted by the same researcher for the sake of consistency. The interviewees were found via a chain-referral sampling approach; in all four cases, the focal entity (known via personal networks) from the specific case provided us with the contact details of other potential interviewees.

Additionally, (online) documentation and company documents were used as secondary data sources. These data sources were used to describe the context of the cases and as complementary sources to the interview results.

The combination of different sources, i.e. triangulation, was used to overcome possible biases and problems that could arise by the use of only one data source. As such, the validity of the results increases (Yin, 2013).

\section{Data analysis}

For the analysis, summaries of the interviews and (online) documentation were generated. Results from the four different cases were constantly compared and merged into a coherent story regarding governance mechanisms.

In the alliance literature (e.g. De Man and Roijakkers, 2008), the implementation of governance mechanisms has been extensively described, whereas in the innovation ecosystem literature its implementation only has been sparsely considered.

To understand the use of governance mechanisms in an innovation ecosystem setting, first data was analysed to have a first grasp of how both trust and control were used in innovation ecosystems.

Then first-order themes were constructed by categorising the data (interview results and documentation) into characteristics that could belong to different types of trust and control. The first-order themes aimed at understanding the characteristics of trust and control within innovation ecosystems.

Then second-order themes were constructed where main constructs from the alliance literature (e.g. output, social, and behavioural control and competence and goodwill trust) were coupled to the different categories of trust and control that were identified within innovation ecosystems. 
The second-order themes were used to relate constructs from the alliance literature to categories of trust and control in an innovation ecosystem context. An overview of the coding can be found in table 1 .

\section{Table 1 Coding and evidence}

\begin{tabular}{|c|c|c|}
\hline Evidence by source & First-order themes & Second-order themes \\
\hline Interviews & $\begin{array}{l}\text { Output not known/constantly changing; } \\
\text { System too dynamic for output definition. }\end{array}$ & Output control \\
\hline $\begin{array}{l}\text { Interviews } \\
\text { Secondary data }\end{array}$ & $\begin{array}{l}\text { Common culture development; } \\
\text { Business meetings; } \\
\text { Joint activities; } \\
\text { Joint goal development; } \\
\text { Coaches; } \\
\text { Communication; } \\
\text { Education; } \\
\text { Community creation. }\end{array}$ & Social control \\
\hline Interviews & $\begin{array}{l}\text { Role definition; } \\
\text { Governance structures; } \\
\text { Responsibility definition; } \\
\text { Conflict management; } \\
\text { Structural agreements. }\end{array}$ & Behavioural control \\
\hline $\begin{array}{l}\text { Interviews } \\
\text { Secondary data }\end{array}$ & $\begin{array}{l}\text { Letter of intent; } \\
\text { Gentleman agreements; } \\
\text { Moral responsibility; } \\
\text { Open communication; } \\
\text { Previous interactions; } \\
\text { Staff attitude. }\end{array}$ & Goodwill trust \\
\hline Interviews & $\begin{array}{l}\text { Required resources and knowledge; } \\
\text { Reputation; } \\
\text { Attractive partners; } \\
\text { Capability to fulfil appointments. }\end{array}$ & Competence trust \\
\hline
\end{tabular}

As innovation ecosystems are a subset of alliances, we presumed that in innovation ecosystems, a comparable concept to alliance management capabilities might be found. Indeed, a comparable construct, i.e. partner alignment stimulator, was found, that also influences the relation between the governance structure and partner alignment.

The governance structure in innovation ecosystems is a combination of several trust and control-based governance mechanisms. We define partner alignment as the extent to which the impact that the focal entity would like to reach by implementing governance mechanisms is in line with how the partners within innovation ecosystems experience the impact of governance mechanisms. An overview of these relevant partner alignment stimulators can be found in table 2 .

Our insights as to how governance mechanisms are implemented emerged inductively, based on our coding and existing literature (Yin, 2013). 
Table 2 Partner alignment stimulators

\begin{tabular}{|c|c|}
\hline Governance type & Relevant partner alignment stimulator \\
\hline Output control & - \\
\hline Social control & $\begin{array}{l}\text { Leadership; } \\
\text { Expectation management; } \\
\text { Trust. }\end{array}$ \\
\hline Behavioural control & $\begin{array}{l}\text { Open discussion; } \\
\text { Communication; } \\
\text { Commitment; } \\
\text { Trust; } \\
\text { Leadership. }\end{array}$ \\
\hline Goodwill trust & $\begin{array}{l}\text { Leadership; } \\
\text { Internal organizational support; } \\
\text { Communication; } \\
\text { Character of organization; } \\
\text { Continuation. }\end{array}$ \\
\hline Competence trust & $\begin{array}{l}\text { Innovation department; } \\
\text { Resource allocation; } \\
\text { Reputation; } \\
\text { Foundation; } \\
\text { Fear of competition; } \\
\text { Representatives; } \\
\text { External factors. }\end{array}$ \\
\hline
\end{tabular}

\section{Case descriptions}

\section{- Sustainability}

In a small municipality in the Netherlands, a diverse group of public and private partners (e.g. educational and governmental organizations and companies) started to collaborate to renovate and exploit an old centre that once focused on projects in the field of living, energy generation, food production, waste processing, and savings on raw materials.

The collaboration aims at creating a sustainable, self-providing community and focuses at four different programs: the built environment, bio-based techniques/food, energy transition, and social transition.

The location itself fulfils educational purposes, inspiration, testing facilities (living labs), and reintegration of people that are distanced from the labour market. As a number of partners are not allowed to take any risks, a foundation was started that aims at the realization of its goals.

\section{- Incubator program}

The remaining cases are also located in the Netherlands, all at a one campus. As the three cases have the same underlying structures, first this structure is briefly explained.

The campus aims at connecting large firms, research institutions, start-ups, and students to innovate together. To stimulate innovation processes, an incubation program has been developed to facilitate the connections between people and eventually stimulate innovation by connecting partners, build a community, and disseminate knowledge within an ecosystem setting. The development program has three different focus areas; blockchain, artificial intelligence and climate change. The innovation process is facilitated by coaches.

Though the following three focus areas are part of the same development program, each case is substantially different in terms of, for example, its maturity, leader, type and numbers of partners, innovation focus, main technology and organizational aspects. Therefore each focus area is treated as a separate case study. Each different focus area 
fulfils the characteristics of an innovation ecosystem. In the following subsections the three different focus areas are briefly explained.

\section{- Blockchain}

Blockchain is trending; firms are increasingly researching its potential impact and (future) applications. Inspired by the trend, blockchain became one of the three focus areas of the incubation program. The blockchain track aims at using advanced, internet-based technology as a potential source of trust, prosperity, equality, and security for society and business. The blockchain track is led by a research organisation specialised in blockchain. Next to a Dutch research organisation, also a banking house, pension fund, consultancy firms and technology firms are part of the ecosystem.

\section{- Artificial intelligence}

Not only blockchain, but also artificial intelligence is an upcoming technological research field. Its potential applications are under research by a wide variety of organisations.

The artificial intelligence project aims at connecting business, research, and education to develop tools to support humans in various situations and provide services for improving business processes. The artificial intelligence case is led by a collaboration of several research institutions.

This collaboration integrates and connects education, business, and research and is a collaboration of different research institutions and universities. Its unique network and knowledge position connects a number of interesting partners that could contribute to innovations in the field of artificial intelligence. Not only an institution, but also consultancy firms, a pension fund, educational organizations, and research institutions take part in the project.

\section{- Climate change}

Whereas the block chain and artificial intelligence tracks were born out of technological trends, the climate change track was inspired by the increasing call for sustainability and the lack of concrete action to reach the goals agreed upon in the Paris Climate Summit.

Next to technological knowledge, it aims at showing the members of the climate change community which impact they have as an individual to inspire them to handle climate change differently inside their company as a professional. In that way, they are stimulated to develop new business models and concepts to, if possible, use new technologies as accelerators.

The climate change track is led by a pension service provider that has a very innovative focus. The company not only integrates its innovative methods in the project, but is also responsible for aligning its activities to the general program, stimulating ecosystem development, and developing use cases.

\section{RESULTS}

We now explain how three types of control and two types of trust are used by focal entities within innovation ecosystems. We also explain for every governance type how its use by the focal entity has influenced the alignment of partners. In table 3 an overview of the representative quotes can be found. 
Table 3 Representative quotes

\begin{tabular}{|c|c|}
\hline Theme & Representative quotes \\
\hline Output control & $\begin{array}{l}\text { - "The desired output has been changing over the years as a result of changes in } \\
\text { employees inside organisations, destination plans, potential subsidies." (Senior } \\
\text { manager governmental organization) } \\
\text { "The output was not clear, but you should not want to have it clear as we are not } \\
\text { working in a solution-driven manner." (Senior manager business) }\end{array}$ \\
\hline Social control & $\begin{array}{l}\text { - "Using key persons that know other persons well, let them have dinner together } \\
\text { and creating open discussions can result in a feeling of trust." (Senior manager } \\
\text { governmental organization) } \\
\text { "Coaches in the project are there to create the right mind set and commitment." } \\
\text { (Middle manager research organization) } \\
\text { - "We made quite some steps, to get everyone on the same knowledge level." } \\
\text { (Senior manager research organization) } \\
\text { "A common point of departure on common problems creates commitment." } \\
\text { (Senior manager business) }\end{array}$ \\
\hline $\begin{array}{c}\text { Behavioural } \\
\text { control }\end{array}$ & $\begin{array}{l}\text { - "There is a functional partnership agreement, but partnership agreement and } \\
\text { - } \quad \text { "It is not clear where responsibilities start and end." (Senior manager foundation) } \\
\text { - "There is no clear leader in the project." (Director educational organization) } \\
\text { - "It is determined upfront for each project how many resources everyone puts in } \\
\text { the project, but capturing is a large word; it rather is discussed verbally." (Middle } \\
\text { manager research organization) } \\
\text { "We search for mental commitment and then we will have a look what roles fit and } \\
\text { which business models." (Senior manager business) }\end{array}$ \\
\hline Goodwill trust & $\begin{array}{l}\text { - "The collective is less collective than the name would imply; the only thing that } \\
\text { - "Whnected them was the location." (Director governmental organization) } \\
\text { each other but eventually you will get to know each other." (Senior manager } \\
\text { banking) } \\
\text { - "We talked about trust, what we will do, what is important, what we want, how we } \\
\text { stand in the projects. Matter of transparency." (Senior manager business) } \\
\text { "As a result of partner X in the collaboration, partner Y was not completely open." } \\
\text { (Senior manager banking) }\end{array}$ \\
\hline Competence trust & $\begin{array}{l}\text { - "It depends per partner, but they certainly have the resources, but it can be } \\
\text { questioned how much they want to allocate to innovation." (Middle manager } \\
\text { research organization) } \\
\text { "Not the right resources in knowledge available as a result of laws and } \\
\text { regulations." (Director business) } \\
\text { "I do think that they have the right resources, but they have to put forward smart } \\
\text { people." (Senior manager business) } \\
\text { "Some organisations have their own innovation department and then you see that } \\
\text { they have time available whereas others do not prioritize it." (Senior manager } \\
\text { business) }\end{array}$ \\
\hline
\end{tabular}

\section{Output control: is it even possible?}

Output control can only be defined when the eventual output of an ecosystem is known (Das and Teng, 1998). Partners in the four innovation ecosystems agreed that the output was constantly changing. We observed that, until now, in three innovation ecosystems solutions were found in surprising fields with unique combinations of partners that could never be imagined upfront. In one innovation ecosystem partners developed a common goal that implied a future output. However, the focal entity soon realized that this output could not be realized within the current setting and that 
output control was not possible, as illustrated by the following quote:

"The desired output as described in the vision document is difficult to be realized with the currently available human capital and money."

(Senior manager governmental organization)

In three innovation ecosystems the goal of the ecosystem was to create disruptive innovation. These innovations can disrupt existing markets, but upfront it is not known whether they will actually disrupt and in what way. One focal entity added that the specific nature of the program the ecosystem belonged to did not allow for a clear upfront view of the output; the program was not working in a solution-driven manner.

As the output was not clear yet and still changing, it was difficult to define how to control it. The ecosystems were not in a stable position yet and still very dynamic as partners were still being added, common goals were being developed, and social consensus was not reached yet. It is questionable whether focal entities are ever able to use output control in innovation ecosystems to manage their enduring dynamic character. As output control was not used, focal entities thus did not influence partner alignment via output control. To summarize, in all four innovation ecosystems output could not be defined neither controlled.

\section{Social control: the power of consensus and socialization}

We observed that social control was widely used by focal entities within innovation ecosystems. Focal entities used social control already at the start of the ecosystem to create social consensus and a feeling of understanding and cohesion. Social control was mainly dominant at the start, as partners did not know each other yet, resulting in a lack of cohesion and consensus. We observed that the implementation of social control was a timeconsuming process for focal entities, as it can be difficult to realize social consensus and a feeling of cohesion; focal entities constantly experimented with respect to how social control could be used. Focal entities used social control as long as they felt that social consensus was not fully reached. At the time of this research, social control was still used in the four innovation ecosystems.

A feeling of consensus was developed via the development of a common culture, the creation of a community, business meetings, joint activities, and joint goal development. In three innovation ecosystems, also coaches were used to create a feeling of commitment and the right mindset and to educate partners to use the same innovation development initiation processes. In one innovation ecosystem, the focal entity explicitly used social control to create commitment via a common point of departure, as illustrated by the following quote: "A common point of departure with respect to common problem creates commitment." (Senior manager business)

Focal entities also used social control to create an innovative community where people no longer represented companies, but themselves. Despite the efforts, in two innovation ecosystems the use of social control did not align partners; several partners felt that no common culture, feelings of cohesion or consensus were found, though the focal entities of these ecosystems felt that these aspects were actually present. The focal entities shared the opinion that a common culture and goal were found, that partners became closer, and that knowledge gaps decreased. Several partners felt that they were not included and that no common culture and goal existed, mainly as a result of only a limited number of face-to-face meetings, as illustrated by the following quote:

"There is no common culture; the members of the management team have seen each other one time this year."

(Director business)

Within one innovation ecosystem, we observed that partners experienced the vision document as written behind a desk, without further considering the actual implementation. Thus a mismatch in expectations was found between the focal entities and the partners of two innovation ecosystems; they experienced the impact of social control differently. It is not clear whether the focal entities ever checked whether the partners experienced a feeling of cohesion and inclusion. The partners within 
these two ecosystems did not feel aligned, though we observed that the partners felt a bit closer at the time of this research than at the start of the ecosystem.

In two innovation ecosystems, focal entities succeeded in aligning partners by the use of social control, as illustrated by the following quote:

"Partners that are collaborating for a while are quicker and more flexible in the innovation process."

(Senior manager banking)

In these innovation ecosystems, partners experienced a common culture and understood the role of the coaches and the way communication was used to cultivate the common culture. One focal entity emphasized that in his ecosystem, the implementation of social control was a time-consuming process, which required many iterations. Social control in this innovation ecosystem was successfully implemented as a result of extensive managerial efforts and constant learning loops. In the second innovation ecosystem, partners experienced social control as being used positively as a result of trust between the partners. Still, partners noted that the common culture could be further improved upon. Overall, the focal entities succeeded in socializing and reaching consensus resulting in partner alignment.

The four innovation ecosystems show that the implementation of social control is a challenging process within innovation ecosystems. Two focal entities did not check whether social consensus was reached. In two out of four innovation ecosystems social control did not have the impact the focal entities aimed for; partners were not aligned. In one innovation ecosystem, this was the result of a lack of leadership; the focal entity did use social control, but most partners did not accept the focal entity as their leader. In the other innovation ecosystem, a lack of trust was found to result in a lack of a common culture. In the other two innovation ecosystems, social control was able to align partners. The focal entities spent quite some effort on the creation of commitment. Also, within these ecosystems, partners accepted the focal entity as their leader and an initial feeling of trust existed. Still, the use of social control could be more efficient when the focal entities would check its effectiveness in practice. Expectation gaps were found between the focal entities and the partners within the innovation ecosystems, strengthening the partners' negative feeling towards alignment. To conclude, leadership, expectation management, and trust were likely influencing the alignment of partners by the use of social control.

\section{Behavioural control: how formal agreements influence people}

In three innovation ecosystems behavioural control was used from the start alongside social control to define roles, design meeting structures, and develop contracts. In one of these three ecosystems, the focal entity explicitly searched for commitment first and then roles were assigned. Within the fourth innovation ecosystem, the focal entity used behavioural control only after the implementation of social control. In fact, behavioural control was used to control the behaviour of the partners in the ecosystem following initial efforts to reach social consensus (Das and Teng, 1998). In that specific case, the focal entity defined partner roles, developed governance structures, defined responsibilities, and created structural agreements. Focal entities mainly used behavioural control to define responsibilities and structures.

Focal leaders felt that behavioural control was successfully implemented, but partners disagreed. Especially within one innovation ecosystem, partners shared the opinion that there was no clear focal entity and that formal agreements were not compatible and based on intentions rather than official agreements. Partners in this ecosystem disagreed regarding the existence and use of conflict management; whereas one partner stated that internal conflict management was organized by the focal entity, the focal entity mentioned that conflicts were handled among partners. In a second innovation ecosystem, we observed that partners lacked understanding of the roles, contexts, and responsibilities, as illustrated by the following quote: 
"There is a difference between program and community management, but what the exact differences are in terms of, for examples, roles is not clear to me."

(Senior manager foundation)

In one innovation ecosystem, the implementation of behavioural control was more successful. Partners understood why roles were specified and why meeting structures existed, as illustrated by the following quote:

"There is a project manager for every project and it is clear why that structure was chosen." (Senior manager foundation)

The focal entity succeeded in the implementation of behavioural control, by stimulating discussions among partners when tensions or conflicts arose and verbally discussing how many resources would be spent on projects. This resulted in a feeling of understanding, transparency, and trust between the focal entity and the partners. The open communication between the focal entity and partners with respect to behavioural control and expectations contributed to the alignment of partners. Whereas one ecosystem succeeded in the use of communication and discussions, we also observed in another innovation ecosystem that when communication and transparency are limited, partner alignment is de-stimulated. As a result of a lack of partner alignment, trust was not present.

Focal entities were challenged to successfully implement behavioural control. In line with social control, a mismatch was found between expectations from the focal entity and the partners in the ecosystem. The focal entities did not check whether behavioural control had the impact they aimed for. In one innovation ecosystem the focal entity did not facilitate open discussion and communication, negatively affecting partner alignment as partners, for example, did not understand which roles existed. In another innovation ecosystem, open discussions and communication were facilitated resulting in a feeling of trust; when the focal entity facilitated open discussions, communication, and transparency among partners, they understood why certain forms of control existed and conflicts were more easily resolved. Again the importance of leadership and trust on partner alignment was found. In one innovation ecosystem, a lack of leadership negatively affected partner alignment; partners did not understand what was expected, therefore not being able to produce the desired results of the focal entity. Also commitment turned out to be an important alignment stimulator, as within one innovation ecosystem we observed that the presence of commitment stimulated partners and the focal entity to get to know each other and discover what motivated partners. When commitment and motivations were understood, it was easier to assign roles that fitted the partners. Again, leadership turned out to be an important influencer. In one specific case, a lack of leadership negatively affected partner alignment; when partners did not understand what was expected of them, they were not able to produce the desired results. We found that partners felt that in the case of shared responsibility, no one is responsible. To conclude, communication, open discussions, trust, leadership, and commitment were influencing the alignment of partners through the use of behavioural control.

\section{Goodwill trust: do people even intend to fulfill their roles?}

The creation of goodwill trust was one of the biggest challenges for the focal entities. All kind of instruments were used to create a feeling of goodwill trust, like letters of intent, gentleman agreements, open communication, and a sense of moral responsibility. Most organizations that were attracted by focal entities already interacted before or were already part of the campus the ecosystem belonged to (in the case of three innovation ecosystems). Though the organizations had interacted before, most representatives of the organizations did not meet or collaborate before. Still, in all innovation ecosystems the majority of partners knew each other indirectly, as illustrated by the following quote:

"A number of people knew each other and together we all knew someone; that was the inspiration for a coalition of the willing."

(Senior manager business) 
One focal entity mentioned that the technological field where the ecosystem was active in represented a small community with many get-togethers. Organizations and representatives in this specific innovation ecosystem already met before at these gettogethers, increasing goodwill trust.

According to the literature, goodwill trust is increased in the case of previous collaborations between partners (Das and Teng, 1998; Das and Teng, 2001). We found that in innovation ecosystems, also partners that did not collaborate before had the feeling that most of their fellow partners had the right intentions, though the intentions of a few were difficult to estimate.

Though commitment was initially low, in three innovation ecosystems goodwill trust increased over time. Still, a number of events limited the presence of goodwill trust and thus partner alignment. In all four ecosystems it was observed that partners that once were part of the system were no longer present, resulting in a decrease of trust. Also, a few partners tended to behave opportunistically within all innovation ecosystems, waiting on others instead of undertaking action themselves.

A number of partners that said to support the general idea, dropped out as soon as discussions started regarding implementation and task division; they only wanted to contribute when they benefitted directly. As a result of opportunistic behaviour, some partners did not dare to speak up as they feared that another partner would steal their ideas, as illustrated by the following quote:

"As a result of partner $X$ in the collaboration, partner $Y$ was not completely open."

(Senior manager banking)

Within one innovation ecosystem, partners felt that the lack of a leader and internal organizational support of representatives and differences between the educational and market organizations prevented partner alignment. In another innovation ecosystem, we observed that partners felt that a number of organizations did not put the right person forward as representative; when representatives did not have the required knowledge or internal support, the alignment of partners was impeded.
Within two innovation ecosystems, it was observed that leadership also can have a positive effect on goodwill trust. We noted that within one ecosystem partners felt that the focal entity was an accountable manager and a natural connector. The focal entity succeeded in increasing commitment and improving partner relations. Within another innovation ecosystem, the focal entity spent quite some time in pushing the partners in the right direction and stimulating open communication about expectations and trust. In both ecosystems, we found that goodwill trust was present.

The examples show that there are a number of factors that influenced the alignment of partners in case of goodwill trust. In all four innovation ecosystems, focal entities tried to stimulate the development of goodwill trust. Not every focal entity was successful in doing so. Especially the role of leadership was found to have an important influence on partner alignment. Also a number of other factors like open communication and the presence of the right representatives were influencing partner alignment.

\section{Competence trust: the importance of knowledge and resources}

The focal entities of all four innovation ecosystems spent quite some time on attracting partners that could contribute the required resources and knowledge. The focal entities realized that attracting organizations with a good reputation and the right representatives would make their ecosystem more attractive, but it was a challenge to attract these partners as a result of both the uncertainty of innovations and external factors.

One focal entity felt that the required knowledge and resources were not available as a result of laws and regulation that made it almost impossible to implement his vision.

Two focal entities felt that in the case of disruptive innovation, it was not known what knowledge and resources were required, making it difficult to know upfront which partners had to be attracted. As it was difficult to attract the "right" partners, it was difficult for the focal entities to create competence trust and to align the partners. 
The difficulty to create competence trust was clearly recognized among the partners. Though focal entities felt that it was difficult to attract the required knowledge and resources, we observed that in two innovation ecosystems partners felt that their partners had the right resources and knowledge. In one innovation ecosystem this was strengthened by the establishment of a foundation. Also, the attraction of well-known organizations increased the feeling that the right resources and knowledge were present.

Despite the fact that partners felt that the required knowledge and resources were available within their partner organizations, still partners felt that the organizations did not allocate the required resources and knowledge to the ecosystem. This resulted in disappointment for a number of partners as they felt that they themselves did allocate substantial resources to the ecosystem.

We found that the allocation of resources and knowledge was related to the presence of an innovation department; organizations that had an innovation department often allowed their employees to spend a certain amount of time and resources on interesting projects, as illustrated by the following quote:

"[...] partners with an independent innovation department are quicker in innovating." (Senior manager banking)

Partners within these two ecosystems felt that organizations with an innovation department allocated more resources and knowledge to the ecosystem. We observed that partners also felt that the allocation of required knowledge and resources was related to having the right representatives of an organization present within the innovation ecosystem. Representatives needed to have both support within their organization and a good network (e.g. to know who to contact in case of a lack of resources). Still, a number of potentially interesting partners were not attracted as partners that were present in the ecosystem feared that these partners could compete with them.

In one innovation ecosystem partners felt that their fellow organizations did not have the required resources and knowledge; they felt that organizations did not have the right structures and employees in place to realize their commitments. Notwithstanding, partners felt that at least the intention existed to meet agreements.

Again, a number of partners felt that a number of organizations did not put the right person forward as a representative. In the fourth innovation ecosystem partners felt that the right knowledge was found, but the required resources to implement it were missing, as illustrated by the following quote:

"I think we potentially have the right knowledge in-house, but there are differences between people with respect to whether they are inspired to deliver it."

(Middle manager governmental organization)

The four cases show that opinions regarding the presence of competence trust were divided; whereas some felt that knowledge and resources were present, but not allocated, others felt that either the knowledge or knowledge and resources were not present. It is difficult to identify the role of the focal entity in partner alignment in the case of competence trust, as the feelings among partners were mainly a result of interactions between partners.

Nevertheless it was found that the presence of the right representatives and an innovation department within organizations stimulated partner alignment. Also having the right external factors, a foundation, and partners with a positive reputation influenced partner alignment.

Focal entities tried to attract organizations that had the right representatives, positive reputations and innovation departments, but external factors and the establishment of a foundation were factors that could not be directly influenced by focal entities.

\section{DISCUSSION}

Based on the findings of this research, we conclude that the focal entity uses social control, behavioural control, competence trust and goodwill trust as governance mechanisms to influence partner alignment. In addition to these governance mechanisms, we found that an 
additional variable exists that influences the effectiveness of governance mechanisms; the partner alignment stimulator. When present, the implementation of governance mechanisms becomes more effective as the impact that the focal entity aimed for is in line with how the partners experienced its impact, resulting in partner alignment. Also, some partner alignment stimulators, like leadership, seem to influence the alignment of partners directly. Focal entities that succeed in implementing partner alignment stimulators effectively, were better able to materialize their value proposition as a result of partner alignment. At first view a number of alliance management capabilities seem to be comparable with partner alignment stimulators, as summarized in table 4 .

Table 4 Capabilities and stimulators

\begin{tabular}{|ll|}
\hline Alliance management capability & Partner alignment stimulator \\
\hline Bonding & Trust, expectation management \\
\hline Communication & Communication \\
Coordination & Leadership \\
\hline
\end{tabular}

When looking at the model as represented in Figure 1, we note that in the case of innovation ecosystems, governance mechanisms are the mediating variable, whereas in alliances alliance management capabilities are the mediating variable. Despite the comparability in terms of the types of capabilities/stimulators, an innovation ecosystem seems to require a substantially different approach from alliances.

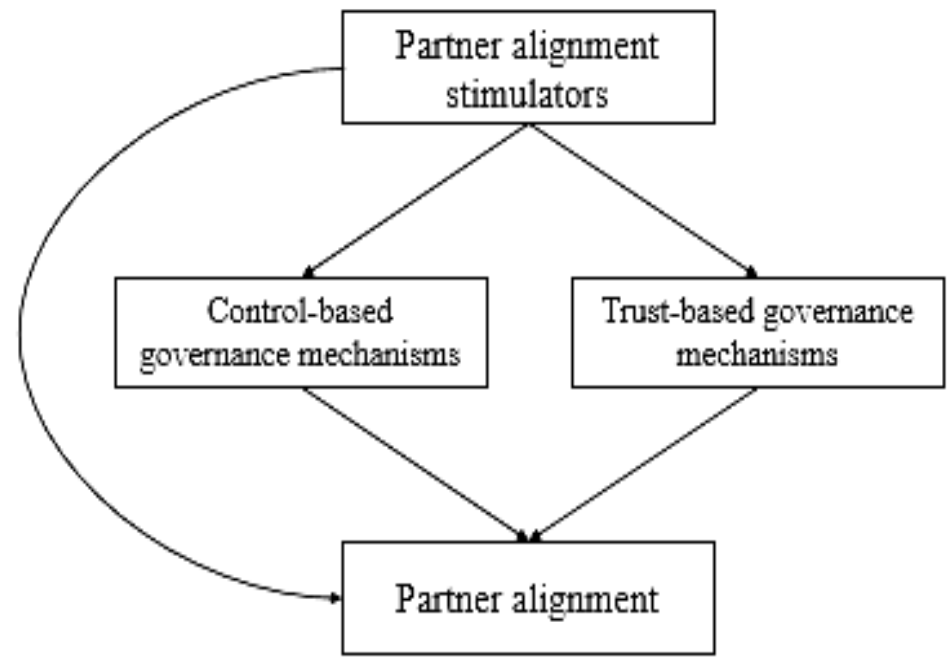

Figure 1 Governance mechanisms and partner alignment stimulators.

In this paper, we have explored how focal entities influence the dynamics within innovation ecosystems by means of governance mechanisms. By doing so, we augment the existing innovation ecosystem literature in a number of ways. First, we augment existing work on innovation ecosystems by studying the implementation of trust and control by focal entities in innovation ecosystems. Until now, the importance of governance mechanisms and their implementation by the focal entity was only sparsely considered in the innovation ecosystem literature and no empirical research was done yet. It was not known yet how governance mechanisms were implemented nor which governance mechanism types were used. This research is among the first that uses empirical research to understand that the 
governance mechanism types as implemented by the focal entity within innovation ecosystems are comparable to governance mechanism types as implemented within alliances.

The main difference between the use of governance mechanisms within innovation ecosystems and the use of these mechanisms in alliances is that within an innovation ecosystem a focal entity implements the governance mechanisms to influence the behaviour of numerous partners, whereas in alliances one firm influences the behaviour of a limited number of partners.

Second, we extend previous work on the impact of governance mechanisms on partners within the innovation ecosystem literature. Scholars had focused on the focal entity as a research object and on what types of governance mechanisms were used. To understand the impact that governance mechanisms have on partners, this research looks beyond the focal entity and integrates the views of different partners.

As a result, we find that different governance mechanisms differ in how they align partners and that different partner alignment stimulators exist that influence the effectiveness of governance mechanisms in aligning partners. Third, we extend previous work on innovation ecosystems regarding the use of partner alignment stimulators. In alliance literature, alliance management capabilities were found that mediate the relation between governance structures and alliance performance. Though innovation ecosystems are a subset of alliances, partner alignment stimulators do not seem to mediate the relation between governance structures and partner alignment; rather, the governance mechanisms seem to be the mediating variable, as seen in Figure 1.

Last, we extend previous work on innovation ecosystems by understanding the relation between governance mechanisms, focal entities, partners, and partner alignment. Until now, no empirical research was done yet on this combination of constructs.

This research explores the applicability of constructs from the alliance literature to an innovation ecosystem context. We find that findings from the alliance literature can be partly applied to innovation ecosystems. Some concepts can be directly applied to innovation ecosystems, whereas some constructs function differently within innovation ecosystems. In an innovation ecosystem context, partner alignment stimulators are used, whereas in an alliance context, alliance management capabilities are used. By thoroughly researching the use of governance mechanisms by focal entities, we were able to create an initial understanding of how its use influences dynamics within innovation ecosystems.

One governance mechanism described in the alliance literature, output control, was not used in innovation ecosystems. In alliances, output control is used to define what the preferred outcome will be at the end of an alliance. Often, alliances work with shorter time frames than innovation ecosystems and the final output is often discussed upfront (Roijakkers and Maes, 2017). Then output control is used to make sure that at the end of the alliance, the desired output is indeed obtained. Innovation ecosystems often focus on disruptive innovation or have a rather broad focus. Also, within innovation ecosystems, it is often not known upfront how long the collaboration will last. As a result, it can be questioned whether these types of ecosystems will ever be able to use output control as they are very dynamic.

This research takes an important step towards further bridging the fields of alliances and ecosystems. As illustrated by table 4, characteristics of different governance mechanisms as used within innovation ecosystems are comparable with definitions from the alliance literature. The list of partner alignment stimulators matches only partly with alliance management capabilities and the effect of both variables was substantially different. Three alliance management capabilities are in line with the partner alignment stimulators that were found. It is not clear yet whether the differences in the effects of partner alignment stimulators and alliance management capabilities are the result of the characteristics of innovation ecosystems or the specific cases.

Also, we do not understand yet why three out of six alliance management capabilities (interorganizational learning, 
sensing, and transformation) are not present in innovation ecosystems. There is a probability that these three alliance management capabilities are not present in the four specific cases that we investigated for this study. It is also possible that they exist, but that we were not able to identify them.

Last, it also could be that these three alliance management capabilities are higherorder stimulators that are not present in emerging innovation ecosystems, and only are revealed in more mature innovation ecosystems. In the four specific cases under study, the focal entities of the four case studies are still struggling with their communication structures, were still bonding, and governance structures were not complete yet. Therefore, we assume that they are not ready yet to, for example, be alert to the environment (sensing), to move beyond routines (transformation) or to build new thinking (interorganizational learning).

\section{Future research directions}

This research has a number of limitations, which also suggest avenues for further research. First, this study is based on an in-depth case study of four innovation ecosystems. Therefore we expect that theoretical insights from this study may only be applicable in an innovation ecosystem context. Next to innovation ecosystems, a number of other ecosystem types have been identified in the literature (e.g. business ecosystem, knowledge-based ecosystem, service ecosystem, etc.).

Future research could explore how governance mechanisms are used by focal entities within other ecosystem types and how the differences between these ecosystems influence the use of governance mechanisms. Some ecosystem types (e.g. service ecosystems) do not have a focal leader as present in innovation ecosystems. It could be interesting for future research to understand how governance mechanisms are used when for example no focal leader is present.

Second, the four innovation ecosystems are active in four specific fields; artificial intelligence, blockchain, sustainability, and climate change. Therefore we expect that the theoretical insights from this study may only be applicable in innovation ecosystems with a comparable focus area, as each different focus area probably has its own specific implications that can influence the use of partner alignment stimulators. Also it is not known yet whether the mismatch between a number of partner alignment stimulators and alliance management capabilities is the result of the specificities of alliances and innovation ecosystems, or whether it is related to the nature of the four cases.

Future research could explore whether governance mechanisms are influenced by comparable partner alignment stimulators in the case of innovation ecosystems with a different focus area. Also it could be assessed whether in different focus areas, comparable partner alignment stimulators are found.

Last, future research could focus on understanding whether the differences between partner alignment stimulators and alliance management capabilities are the result of specificities of ecosystems compared to alliances, or that partner alignment stimulators are case-specific.

Third, the four cases represent relatively young innovation ecosystems that are still in the development phase. We selected these kinds of innovation ecosystems since only in starting innovation ecosystems alignments structures are still being developed (Adner, 2017). As a result, the findings are only applicable to emerging innovation ecosystems.

Future research could focus on more mature innovation ecosystems to understand whether the role of governance mechanisms changes over time and whether the importance of partner alignment stimulators still exists in later stages. Its understanding can contribute to the continuous stimulation of partner alignment in later stages of ecosystem development.

Therefore we recommend that future researchers undertake longitudinal studies to understand how governance mechanisms and partner alignment stimulators develop over time. Also, in more mature innovation ecosystems the role of output control could be investigated, assuming that the output is more predictable in these stages. Therefore it could be interesting to investigate whether output 
control can be used in more mature innovation ecosystems.

Fourth, as three out of four cases belong to the same program and the fourth ecosystem was completely independent from the program, generalizability may not be optimal. We found similarities among three out of four cases in terms of, for example, behavioural and social control. Still, these three cases were substantially different in terms of, for example, the number of partners, the technology used, and the focal entity.

The fourth case differed substantially from the other three with respect to, for instance, the institutional environment and location. To increase generalizability, future research could focus on cases that are more comparable (e.g. all having a comparable institutional context).

Fifth, the findings of this research are based on constructs from the alliance literature. Though innovation ecosystems are a subset of alliances, it is discussable whether these constructs can be applied directly to an innovation ecosystem context. We found that governance mechanisms from the alliance literature could be applied to innovation ecosystems when partner alignment stimulators were added.

With respect to alliance management capabilities, however, only three out of six capabilities were recognized in innovation ecosystems while we assumed that the other three would also be present and the relations were different.

Future research could focus on studying the use of partner alignment stimulators in more mature innovation ecosystems to understand whether the three management capabilities are either not present in innovation ecosystems or that they are only employed in later stages of development.

Last, the findings in this research are based on an explorative, in-depth multiple case study.

To increase the understanding of partner alignment stimulators and to test how strong their influence is on the effectiveness of governance mechanisms, future research could focus on the use of more elaborate quantitative research methods. Several scholars have made an attempt to define how alliance management capabilities can be measured (Schreiner et al., 2009; Schilke and Goerzen, 2010).

\section{Managerial recommendations}

We discovered a list of relevant partner alignment stimulators that enhance the effectiveness of governance mechanisms. It is important for managers to consider these stimulators when starting an innovation ecosystem. First, we recommend that managers consider the importance of leadership as it turned out to be one of the most important partner alignment stimulators.

A manager should understand that innovation ecosystems require different management capabilities compared to existing management practices; a manager should be a natural connector, listener, visionary, decisionmaker, and expert. Also an effective manager should be able to make decisions regarding the future of the ecosystem (top-down) and, at the same time, he should be able to co-create with partners (bottom-up).

A manager has to be flexible; he should take on different roles, depending on what a specific situation needs. To increase the success of innovation ecosystems, we recommend that managers consider the characteristics as described above when hiring future managers.

Also we recommend that focal entities consider important leadership characteristics when managing an innovation ecosystem and educate the individuals that will lead an innovation ecosystem.

Second, and related to the first implication, we recommend that managers consider the importance of communication and management structures. A manager has to understand that every partner has its own specific uncertainties and ways to deal with them as well as his personal expectations. Only when a partner feels that a manager or focal entity understands him, he will do the best he can to perform.

To understand his partners, a manager should be transparent, open, thorough, and a good listener. These characteristics will 
contribute to a sense of transparency and openness among the focal entity and partners. Also, structures can be designed to effectively manage the expectations of partners. Managers need to be transparent and open to ensure that partners feel that they can share their concerns and expectations.

To increase the success of innovation ecosystems, we recommend that managers have open and transparent communication structures in place and design an expectation management structure.

Last, we recommend that managers consider the importance of resource allocation. Only when every partner contributes resources and knowledge to the innovation ecosystem, it will be possible to create synergies and to innovate collaboratively. For some partners it is difficult to find support within their own organizations for the allocation of resources, whereas some partners simply do not have the required knowledge and resources. Another group of partners may not prioritize resource allocation to the ecosystem.

Managers should understand why partners are not allocating resources to the ecosystem. When, for example, the required resources or knowledge are not available, managers could negotiate with a partner the contribution of resources that they do have. To increase resource allocation, we recommend that managers first investigate why partners are not allocating resources to the ecosystem and only then take appropriate actions.

\section{REFERENCES}

Adner, R. (2006). Match Your Innovation Strategy to Your Innovation Ecosystem. Harvard Business Review, 84: 98-107.

Adner, R. (2017). Ecosystem as Structure: An Actionable Construct for Strategy. Journal of Management, 43: 39-58.

Adner, R., \& Kapoor, R. (2010). Value creation in innovation ecosystems: how the structure of technological interdependence affects firm performance in new technology generations, Strategic Management Journal, 31: $306-333$.
Anand, B.N., \& Khanna, T. (2000). Do firms learn to create value? The case of alliances. Strategic Management Journal, 21: 295-315.

Autio, E., \& Thomas, E.D.W. (2014). Innovation ecosystems: Implications for innovation management? In Dodgson, M., Gann, D.M., \& Philips, N. (ed) The Oxford Handbook of Innovation Management, pp. 204-228, Oxford University Press: Oxford, UK.

Bercovitz, J., Jap, S. D., \& Nickerson, J. A. (2006). The Antecedents and Performance Implications of Cooperative Exchange Norms. Organization Science, 17:6: 724-740.

Boudreau, K. (2010). Open platform strategies and innovation: Granting access vs. devolving control. Management Sciences, 56: 1849-1872.

Child, J. (2001). Trust: The fundamental bond in global collaboration. Organizational Dynamics, 29:4: 274-288.

Das, T.K., \& Teng, B. (1998). Between Trust and Control: Developing Confidence in Partner Cooperation in Alliances. The Academy of Management Review, 23:3: 491-512.

Das, T.K., \& Teng, B. (2001). Trust, Control, and Risk in Strategic Alliances: An Integrated Framework. Organization Studies, 22:2: 251283.

Dekker, H.C. (2004). Control of interorganizational relationships: evidence on appropriation concerns and coordination requirements. Accounting, Organizations and Society, 29: 27-49.

Eisenhardt, K.M. (1989). Building Theories from Case Study Research. The Academy of Management Review, 14:4: 532-550.

Eisenhardt, K.M., \& Graebner, M.E. (2007). Theory building from cases: opportunities and challenges. Academy of Management Journal, 50:1: 25-32. 
Faems, D., Janssens, M., Madhok, A., \& Looy, B.v. (2008). Toward an Integrative Perspective on Alliance Governance: Connecting Contract Design, Trust Dynamics and Contract application. The Academy of Management Journal, 51:6: 1053-1078.

Gobble, M.M. (2014). Charting the Innovation Ecosystem. Research-Technology Management, 57:4: 55-59.

Gomes, L.A.d.V., Salerno, M.S., \& Phaal, R., Probert, D.R. (2018). How entrepreneurs manage collective uncertainties in innovation ecosystems. Technological Forecasting \& Social Change, 128: 164-185.

Gulati, R. (February 1995). Does Familiarity Breed Trust? The Implications of Repeated Ties for Contractual Choice in Alliances. The Academy of Management Journal, 38:1: 85-112.

Gulati, R., Puranam, P., \& Tushman, M. (2012). Meta-organization design: Rethinking design in interorganizational and community contexts. Strategic Management Journal, 33:6: 71-86.

Hagedoorn, J., Roijakkers, N., \& Kranenburg, $H$. (2008). The formation of subsequent interfirm R\&D partnerships between large pharmaceutical companies and small, entrepreneurial biotechnology firms - how important is inter-organisational trust? International Journal of Technology Management, 44:2: 81-92.

Jacobides, M.G., Cennamo, C., \& Gawer, A. (2018). Towards a theory of ecosystems. Strategic Management Journal, 39:8: 22552276.

Kale, P., Dyer, J.H., \& Singh, H., (2002). Alliance capability, stock market response and long-term alliance success: the role of the alliance function. Strategic Management Journal, 23:8: 747 -767.

Leavy, B. (2012). Interview - Ron Adner: managing the interdependencies and risks of an innovation ecosystem. Strategy \& Leadership, 40:6: 14-21.

Leroi-Werelds, S., Pop, O., \& Roijakkers, N. (n.d.). Understanding value creation in alliance ecosystems: insights from marketing. In Das, T.K. (ed), City University of New York.

Lopes-Berzosa, D., \& Gawer, A. (2014). Innovation Policy within Private Collectives: Evidence on 3 GPP's Regulation Mechanisms to Facilitate Collective Innovation. Technovation, 34:12: 734-745.

Madhok, A., \& Tallmann, S.B. (1998). Resources, transactions and rents: managing value through interfirm collaborative relationships. Organization Science, 9:3: 326339.

Man, A.d. (2006). Alliantiebesturing. Samenwerking als precisie-instrument. Koninklijke Van Gorcum BV: Assen.

Man, A.d., \& Roijakkers, N (2008). Zijn allianties te besturen? Beheersing en vertrouwen in samenwerkingsverbanden. $M \& O$, 3:4.

Meier, M., Lütkewitte, M., Mellewigt, T., \& Decker, C. (2016). How managers can build trust in strategic alliances: a meta-analysis on the central trust-building mechanisms. Journal of Business Economics, 86: 229-257.

Möller, K., Rajala, A., \& Svahn, S. (2005). Strategic business nets: their type and management. Journal of Business Research, 58: 1274-1284.

Lui, S.S., \& Ngo, H. (2004). The role of Trust and Contractual Safeguards on Cooperation in Non-equity alliances. Journal of Management, 30:4: 471-485.

Mercan, B., \& Göktas, D. (2011). Components of Innovation Ecosystems: A CrossCountry Study. International Research Journal of Finance and Economics, 76: 103-112. 
Parkhe, A. (1993). Strategic Alliance Structuring: A Game Theoretic and Transaction Cost Examination of Interfirm Cooperation. The Academy of Management Journal, 36:4: 794829.

Poppo, L., \& Zenger, T. (2002). Do formal contracts and relational governance function as substitutes or complements? Strategic Management Journal, 23:8: 707-725.

Roijakkers, N., \& Hagedoorn, J. (2006). Inter-firm R\&D partnering in pharmaceutical biotechnology since 1975: Trends, patterns, and networks. Research Policy, 35:3: 431-446.

Schreiner, M., Kale, P., \& Corsten, D. (2009). What really is alliance management capability and how does it impact alliance outcomes and success? Strategic Management Journal, 30: 1395-1419.

Schilke, O., \& Goerzen, A., (2010). Alliance Management Capability: An Investigation of the Construct and Its Measurement. Journal of Management, 36:5: 1192-1219.
Sundaramurthy, C., \& Lewis, M. (2003). Academy of Management Review, 28:3: 397415.

Vanhaverbeke, W. (2017). Managing Open Innovation in SMEs. Cambridge University Press: Cambridge.

Van de Ven ,A.H., \& Polley, D., (1992). Learning while innovating. Organization Science, 3:2: 92-116.

Wang, P. (March 15, 2009). An Integrative Framework for Understanding the Innovation Ecosystem. Advancing the Study of Innovation and Globalization in Organizations.

Wathne, K., Heide, J.B. (2000). Opportunism in Interfirm Relationships: Forms, Outcomes, and Solutions. Journal of Marketing, 64:4: 36-51.

Williamson, O.E. (1975). Markets and hierarchies. New York, 2630.

Yin, R.K. (May, 2013). Case Study Research. Design and Methods. Sage Publications Inc: California. 